\title{
Os saberes do professor de Geografia (1)
}

\author{
The knowledge skills of the Geography teacher
}

\author{
Bruno Saggiorato'; Ricardo Carvalho Leme"
}

\begin{abstract}
RESUMO
Neste texto procuramos identificar quais são os saberes que qualificam o professor de Geografia, ou seja, os conhecimentos que esses profissionais mobilizam para exercerem seu trabalho. Destarte, usamos a pesquisa bibliográfica, centrando-se fundamentalmente nas contribuições de Tardif. Para ser professor de Geografia são necessários diversos saberes, tanto das ciências educacionais quanto da ciência geográfica. Ademais, constatamos que os professores produzem seus próprios saberes no exercício da profissão, ainda que esses sejam amplamente desvalorizados. Partilhamos da ideia de que os professores de Geografia possuem um papel imprescindível na formação cidadã dos estudantes, pelo fato da profissão ser essencialmente humana e por essa ciência possibilitar uma leitura das contradições que o espaço geográfico apresenta. Este trabalho, no que se refere a sua contribuição, buscou trazer uma discussão teórica relevante no estudo dos saberes profissionais dos professores de Geografia.
\end{abstract}

Palavras-chave: Saberes Profissionais; Geografia; Docência

\section{ABSTRACT}

In this text we seek to identify what knowledge qualifies the geography teacher, the knowledge skills that those professionals mobilize to carry out their work. Thus, we use bibliographic research, focusing primarily on Tardif's contributions. To be a professor of Geography, it is necessary to have several types of knowledge skills, in educational sciences and also geographic science. Along this research, we found out that teachers produce their own knowledge in the exercise of the profession, even though these are largely devalued. We share the idea that Geography teachers have an essential role in the citizens' education of students, especially because the profession is essentially human and because this science allows a discussion about the contradictions that the geographical space presents. This work, with regards to its contribution, sought to bring a relevant theoretical discussion in the study of the professional knowledge skills of Geography teachers.

Keywords: Teaching; Professional Knowledge; Geography 


\section{INTRODUÇÃO}

No artigo em questão abordamos os saberes profissionais docentes, investigando quais são esses saberes, sua origem e características, bem como o seu processo de constituição pelo docente. Outrossim, objetivamos apresentar especificamente os saberes do professor de Geografia, pois, estes possuem algumas particularidades devido a ciência com qual trabalha.

Os saberes profissionais são o conjunto de conhecimentos plurais e oriundos de diversas fontes que o professor desenvolve ininterruptamente durante a vida. Esses saberes são avaliados, reorganizados e atualizados pelos professores na prática da sala de aula e em contato com os diversos sujeitos no ambiente de trabalho (TARDIF, 2014). Outro aspecto a se considerar é a responsabilidade do professor de Geografia na formação cidadã, pois ao trabalhar essa disciplina encontra conteúdos essenciais na compreensão do mundo pelos olhos desse campo científico, isto é, como se deu ao longo do tempo a relação dialética entre os homens e destes com a natureza e sua consequente produção, reprodução, transformação e organização do espaço geográfico. A motivação em realizar este trabalho se deu pela necessária discussão a respeito da formação de professores de Geografia vinculada à um corpo de saberes mais amplo, que possibilite uma formação que atenda as demandas da profissão. Também se justifica pelo desejo de compreender melhor o tema, visto que os autores que assinam este texto estão inseridos profissionalmente como professores de Geografia. Referente a metodologia, fizemos uso da pesquisa bibliográfica, por meio de artigos científicos, teses e livros sobre o tema, de autores como Tardif (2014), Lopes (2010 e 2016), Callai (1995 e 2013), Mormul (2018a e 2018b), Girotto (2014), Santos (1977), entre outros.

Além desta introdução e das considerações finais, o artigo está organizado em dois momentos, no primeiro investigamos os saberes docentes, sua origem, formação, sujeitos e situações envolvidas, no segundo tratamos da caracterização dos saberes profissionais do professor de Geografia. 


\section{OS SABERES DOCENTES, SUA NATUREZA, CARACTERIZAÇÃO E FORMAÇÃO}

O saber difere do conhecimento científico. Pois, o primeiro não é necessariamente metódico e formal, porém ambos são correlatos. O saber ou a sabedoria antecede a ciência, o homem desenvolve um saber para resolver uma situação de momento e este posteriormente é organizado metodicamente constituindo assim um conhecimento científico (LOPES, 2010).

Para compreendermos o processo que envolve a internalização dos saberes docentes, faz-se necessário neste momento investigarmos suas características e sua origem, precisamos desvendar esses atributos para também entendermos de que maneira eles refletem a prática docente na escola. Esta tarefa tem amparo principalmente nas pesquisas elaboradas por Maurice Tardif (2014).

Assim, para Girotto e Mormul (2016), Tardif almeja entender a dinâmica que envolve os saberes dos professores, que em síntese são uma pluralidade de conhecimentos ou habilidades de diversas origens e temporalidades, que mobilizadas se manifestam no cotidiano do professor e que submetidos ao ato reflexivo da prática profissional são reorganizados com frequência. Assim, essa perspectiva posiciona-se de maneira antagônica à concepção que reduz a atividade docente em mera execução técnica.

Lopes (2016) destaca o fenômeno da educação tecnicista afirmando com uma metáfora que o professor é percebido, nas palavras do autor, como "um papagaio destituído de saberes", que apenas reproduz conhecimentos formulados por outras pessoas, “[...] o cientificismo moderno, ao separar o trabalhador de seus saberes, desqualificou o ser profissional, transformando a profissão em um ato mecânico de simples reprodução, baseado em destrezas técnicas [...]" (LOPES, 2016, p. 24).

Ainda nesta linha de raciocínio, Lopes (2016) afirma que os saberes dos professores fazem resistência a simples redução de um conjunto de competências, ou do saber fazer, advindo do tecnicismo na educação. A qualidade do profissional professor procede de um complexo e rigoroso processo de domínio teórico, científico e reflexivo, assim, a docência desejada 
[...] não é um dom, embora alguns o tenham; não é uma técnica, embora requeira uma excelente operacionalização técnicoestratégica; não é uma vocação, embora alguns a possam sentir. É ser um profissional de ensino, legitimado por um conhecimento específico exigente e complexo [...] (ROLDÃO, 2007, p. 102).

Desta forma, um bom professor deve contar com uma formação inicial que dê conta de abordar os saberes científicos e teóricos que serão necessários futuramente. Portanto, os saberes são plurais e provenientes de diferentes fontes, como tentaremos demonstrar adiante.

O saber dos professores inegavelmente é um saber social, pois antes de tudo os professores possuem uma formação comum, apesar de algumas particularidades distintas, o objetivo traçado é compartilhado por todos, em segundo lugar realizam um trabalho coletivo, sob condições profissionais (encaminhamentos, regras, parâmetros, etc.) muito semelhantes e exercem suas funções em instituições que seguem objetivos similares (TARDIF, 2014).

Os saberes que os professores mobilizam possuem dupla elaboração: i) realizados cientificamente por pessoas especializadas no campo educacional ou na disciplina de atuação; ii) elaborado individualmente ou coletivamente pelos próprios docentes a partir da autoavaliação de suas práticas no trabalho (LOPES, 2010).

Em suma, a atuação de um professor jamais se realizará sem que haja a interação com outros sujeitos ou com instituições originalmente da sociedade, como por exemplo, os seus estudantes e a universidade, e mais, o docente não decide sozinho a gama de saberes científicos que irá aprender para tornar-se um profissional, consequentemente também não define o que irá ensinar nas escolas, todas essas questões são debatidas, organizadas e efetuadas por um coletivo de pessoas (TARDIF, 2014).

Por conseguinte, fica explícito que os saberes docentes são resultado de uma construção histórica, de embates de ideias e relações de poder. Levando-se em conta a importância na sociedade da profissão professor, conquanto desvalorizada, é 
importante ficarmos atentos com essas questões para que possamos compreender as intenções daqueles que formulam os documentos oficiais e as políticas relacionadas à educação (carregadas de uma visão de mundo específica) que balizam e influenciam a atividade docente.

Deste modo, “[...] a atividade docente é uma prática social, historicamente construída, que transforma os sujeitos pelos saberes que vão se constituindo, ao mesmo tempo em que os saberes são transformados pelos sujeitos dessa prática [...]" (FRANCO, 2009, p. 13). Todos esses elementos tratados a pouco mostram que de fato os saberes docentes são sociais, permeado por embates entre grupos sociais, isto é, luta de classes, assim, é introduzido uma forma de pensar, princípios e políticas que irão perpassar os encaminhamentos que envolvem a educação de forma geral em um país ou região.

Compreendido essa característica importante dos saberes docentes, a saber, a intrínseca relação com a sociedade e o modo como ela se organiza, investigaremos que saberes são esses, suas origens e de que maneira se formam. Estamos convencidos de que esses saberes são múltiplos e mutáveis, pois não provém de uma única origem e constantemente são aperfeiçoados em temporalidades diversas, alterando-se ao longo da vida. Assim, os saberes constituídos são anteriores e posteriores à formação inicial (TARDIF, 2014).

Os saberes profissionais dos professores parecem ser, portanto, plurais, compósitos, heterogêneos, pois trazem à tona, no próprio exercício de trabalho, conhecimentos e manifestações do saber-fazer e do saber-ser bastante diversificados e provenientes de fontes variadas, as quais podemos supor também que sejam de natureza diferente [...] (TARDIF, 2014, p. 61).

O quadro a seguir pretende dar conta de explicitar o conteúdo da citação anterior, mostrando os conhecimentos que influenciam e são a base da atividade docente. 
Quadro 1: Os saberes dos professores

\begin{tabular}{|c|c|}
\hline $\begin{array}{l}\text { Saberes dos } \\
\text { professores }\end{array}$ & $\begin{array}{l}\text { Fontes sociais } \\
\text { de aquisição }\end{array}$ \\
\hline Saberes pessoais & $\begin{array}{l}\text { A família e o contexto social, econômico e cultural que estão } \\
\text { inseridos, etc. }\end{array}$ \\
\hline $\begin{array}{l}\text { Saberes da formação escolar } \\
\text { anterior }\end{array}$ & Educação básica \\
\hline $\begin{array}{l}\text { Saberes construídos na } \\
\text { formação profissional }\end{array}$ & $\begin{array}{c}\text { Instituições de formação inicial de professores, cursos, } \\
\text { estágios, etc. }\end{array}$ \\
\hline $\begin{array}{ll}\text { Saberes advindos } & \text { das } \\
\text { diretrizes educacionais } & \end{array}$ & Currículos, programas e políticas para a educação \\
\hline $\begin{array}{l}\text { Saberes da sua própria } \\
\text { experiência na profissão }\end{array}$ & $\begin{array}{c}\text { A prática do professor em interação com a escola, os } \\
\text { estudantes e colegas }\end{array}$ \\
\hline
\end{tabular}

Fonte: reelaborado pelo autor com base em Tardif (2014)

O quadro explicita a variedade e as diversas origens dos saberes que os professores mobilizam para sua prática, estes realmente influenciam suas aulas, como por exemplo os saberes pessoais, os valores e as condutas que são comumente recorridos como critérios em escolhas cotidianas na profissão (TARDIF, 2014).

Isto ocorre igualmente com os saberes oriundos das políticas educacionais, os currículos e programas, esse conjunto de diretrizes norteiam o trabalho docente, estando o profissional consciente ou não deste fato e das suas implicações práticas. Vê-se, portanto, que a formação de um professor tem fontes variadas de saberes que se entrecruzam em um processo de construção complexo, não se trata de uma simples transposição de conhecimentos teóricos.

Podemos atribuir aos professores alguns elementos que lhe dão uma certa especificidade em relação as demais profissões, não é uma atividade predominantemente mecânica ou técnica, daí a necessidade de um corpo de saberes variados para suprir as exigências dessa tarefa. A atividade docente é essencialmente humana e somente está característica nos revela quão desafiadora ela é. 
[...] O profissional que um curso de graduação-licenciatura forma vai trabalhar com educação, com o processo de ensinoaprendizagem de um determinado conteúdo que é parte do currículo do primeiro e do segundo grau. A sua prática não é construir coisas, organizar/administrar problemas, ensinar/treinar certas técnicas, mas é educar. E educar entendemos que seja criar as condições, instrumentalizar pessoas para que tenham acesso concretamente à sua cidadania, e ao exercício dela (CALLAl, 1995, p. 40).

Considerando que a profissão é essencialmente humana, ora, é fundamental reforçarmos a importância e a valorização nos cursos de formação de professores de conhecimentos que possibilitem o profissional compreender satisfatoriamente as questões humanas ligadas ao ensino, como por exemplo, a aprendizagem e o comportamento, entre outros. Isto, porém, não significa primazia desses conhecimentos ou o abandono do conteúdo e das teorias de cada ciência.

Nessa perspectiva, consideramos ainda que a atividade do professor, na relação ser humano e ser humano, exige tarefas como instruir, mediar, compreender, colaborar, entreter, cuidar, divertir etc. essas ações estão vinculadas ao uso da linguagem e da comunicação (TARDIF e LESSARD, 2009).

Na prática, os saberes (os que o professor possui) durante uma determinada situação são utilizados pelo docente, que posteriormente (em um tempo não definido) avalia o resultado de suas ações, buscando (por intermédio da pesquisa) novos conhecimentos que o possibilitem tomar decisões mais acertadas no futuro. Esses novos saberes confrontam-se e reorganizam-se, desenvolvendo sua capacidade de enfrentar situações do dia a dia.

Por este ângulo, enxergamos um horizonte contrário ao tecnicismo da atividade docente, ou seja, em que o professor apenas reproduz aqueles saberes que the são ensinados, ao invés de excluir sua realidade no trabalho, esta tem um papel fundamental. Isto posto, reconhecemos o professor como também produtor dos seus saberes (LOPES, 2016). 
Pela inerência da profissão professor, como mostramos, essencialmente humana, há outro importante atributo, trata-se da forte relação da personalidade do professor com o desenrolar da sua aula. Ou seja, quando entramos em sala não há possibilidade de desligarmo-nos daquilo que somos e acreditamos.

Ao longo dos últimos anos, temos dito (e repito) que o professor é a pessoa e que a pessoa é o professor. Que é impossível separar as dimensões pessoais e profissionais. Que ensinamos aquilo que somos e que, naquilo que somos, se encontra muito daquilo que ensinamos [...] (NÓVOA, 2009, p. 38).

Percebemos que o profissional e o pessoal inevitavelmente estão presentes nos conteúdos trabalhados, expondo visões políticas, culturais, princípios éticos, em suma, a forma como se enxerga e interpreta o mundo, e no caso da Geografia esse aspecto é mais explícito em virtude do caráter dessa ciência.

Se levarmos em conta que o professor possui um papel fundamental na formação humana e científica dos estudantes e há evidências práticas para confiar nisso, então é inequívoco que há uma grande responsabilidade do profissional, embora não realize sozinho sua tarefa, é inegável sua influência - especialmente dos professores de Geografia - na formação dos futuros cidadãos.

Essa responsabilidade que tratamos demanda uma formação profissional sólida.

[...] em suma, o professor ideal é alguém que deve conhecer sua matéria, sua disciplina e seu programa, além de possuir certos conhecimentos relativos às ciências da educação e à pedagogia e desenvolver um saber prático baseado em sua experiência cotidiana com seus alunos (TARDIF, 2014, p. 39)

Já demonstramos alguns aspectos que envolvem a atividade docente, deixando claro que para dar conta das demandas se faz necessário conhecer outros saberes para além dos da ciência em questão. Tardif (2014) defende a necessidade de quatro saberes: 1) profissionais; 2) curriculares; 3) disciplinares; e 4) experenciais. 
Os saberes profissionais: são saberes oriundos das ciências da educação, resultado da reflexão teórica da prática docente, embora seja raro ver esses cientistas diretamente atuando nas escolas. Normalmente esses conhecimentos são apresentados no decorrer do curso de formação de professores e tem entre seus objetivos não apenas produzir teorias, mas também incorporá-las à ação docente. (TARDIF, 2014).

Os saberes curriculares: dizem respeito as normativas e encaminhamentos dos currículos da escola, estes irão nortear o trabalho do professor em sala de aula, como por exemplo, os objetivos, os conceitos e os projetos que a instituição escolar adota. Esses saberes são influenciados pelas diretrizes educacionais estabelecidas nacionalmente e que também sofrem influência, no caso brasileiro por exemplo, de políticas educacionais formuladas em âmbito mundial pelos países desenvolvidos (TARDIF, 2014).

Os saberes disciplinares: são os conhecimentos sociais de um campo científico, a Geografia por exemplo, acumulados historicamente pela humanidade. Esses saberes são selecionados e ofertados pelas universidades em seus cursos de formação, tratase de um rol de disciplinas selecionadas para compor a grade curricular de uma licenciatura (TARDIF, 2014).

Os saberes experenciais: diferentemente dos demais saberes, este não advém de currículos ou das universidades de formação, são práticos, conhecimentos desenvolvidos pelos próprios professores, que gozam de uma certa autonomia na sua elaboração, mesmo que ainda não valorizados devidamente. Na prática de sua função cotidiana os professores a partir de sua experiência produzem seus saberes (TARDIF, 2014). 
Imagem 1: os saberes profissionais docentes

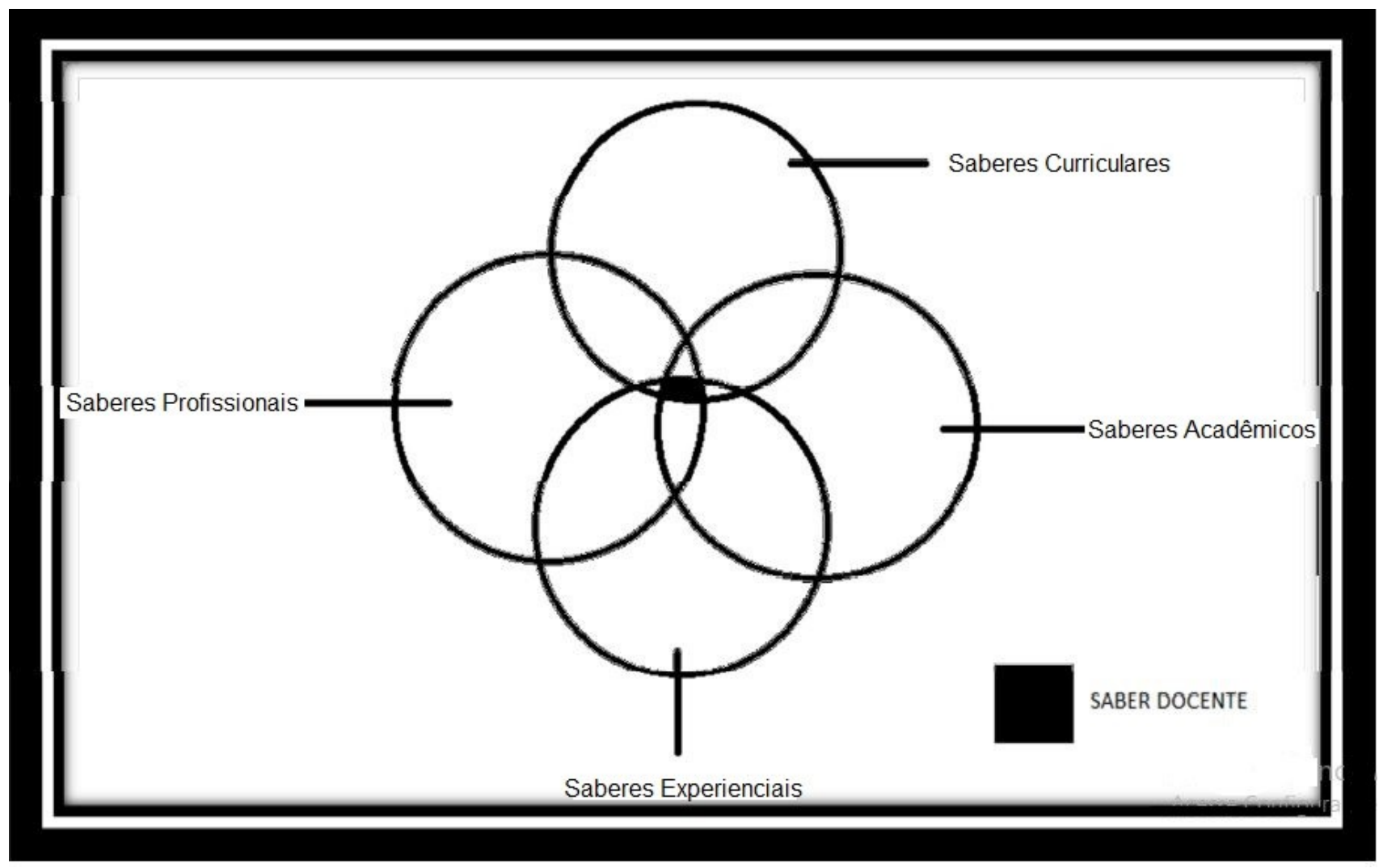

Fonte: GIROTTO, 2013, p. 46

Referente aos saberes profissionais ou pedagógicos, podemos dizer que são com frequência desvalorizados nos cursos de formação de professores, concebidos como conhecimentos menos importantes ou desnecessários. Recentemente esses conhecimentos vêm ganhando espaço nos cursos de licenciatura, um avanço significativo para a qualificação profissional dos futuros professores.

Sobre os saberes experenciais e sua importância, "A experiência se dá quando somos capazes de refletir e produzir sentidos e significados para aquilo que nos acontece [...]" (GIROTTO, 2014, p. 47). Desta forma, esse processo reflexivo resulta na produção de seus próprios saberes.

A prática se constitui como um processo contínuo de aprendizagem, pois "A experiência provoca, assim, um efeito de retomada crítica (retroalimentação) dos saberes adquiridos antes ou fora da prática profissional" (TARDIF, 2014, p. 53), 
permitindo que os professores realizem uma autoavaliação dos seus saberes confrontando-os com a realidade.

Consideramos importante elencarmos algumas características dos saberes experenciais. Estão intimamente relacionados com a ação do professor; se trata de um saber prático e plural; é um saber dinâmico, construído a partir da interação do professor com outros sujeitos da escola; é um saber heterogêneo, possui origens diversas, é adquirido em momentos e locais diferentes da história do professor; é um saber inacabado e complexo, está em constante remodelação sem deixar de lado a personalidade do docente (TARDIF, 2014).

É válido dizer que Lopes (2010) concorda com Tardif (2014) ao afirmar que estes saberes mencionados não fazem parte de uma "receita" e nem mesmo garantem que sejam suficientes na prática profissional, eles são um norte, com o objetivo de auxiliar e não definir, pois sabemos que os saberes estão constantemente sujeitos a transformações.

Em relação a maneira como os professores relacionam-se com esses saberes, Tardif (2014) assinala que ainda que sejam praticados e incorporados à prática, não são produzidos ou legitimados por ela. Ademais, a relação estabelecida aqui é de preceptores de seus saberes e não produtores, daí a relevância da valorização dos saberes experenciais, elaborados pelos docentes mediante sua prática.

Portanto, tentamos mostrar até aqui alguns aspectos sobre os saberes dos professores, vimos que são conhecimentos mobilizados pelos docentes derivados de diversas fontes, construídos em diferentes momentos e constantemente aperfeiçoados por meio da reflexão da prática, processo esse, a propósito, que permite aos professores elaborarem seus próprios saberes.

Evidentemente que, a auto avaliação construtiva depende de instrumentais adequados a esse processo, geralmente apreendidos no corpo de conhecimentos ofertados na formação docente e depende ainda de condições de trabalho que permitam concretamente o desenvolvimento dos saberes experenciais dos professores. Contudo, o quadro que enxergamos por regra é o que segue. 
Imagem 2: O trabalho docente

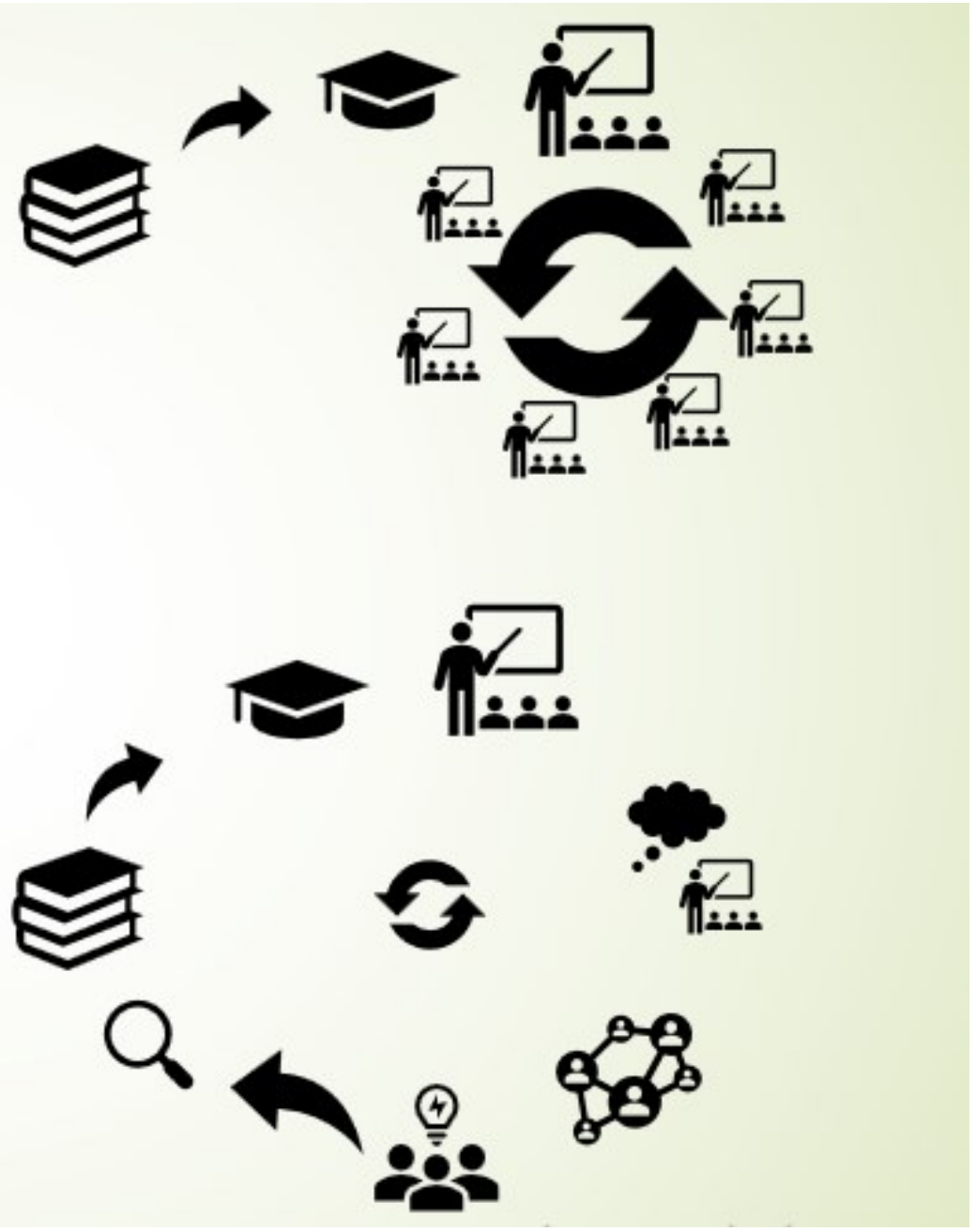

Fonte: organização dos autores, 2019

Para clarificar, são duas realidades que pretendemos ilustrar, na primeira e genericamente a mais frequente, o profissional adquire uma formação no ensino superior e quando este passa a atuar nas escolas, é confrontado com condições de trabalho sob a primazia da prática ou do fazer em si mesmo, comprometendo outra dimensão da profissão, qual seja, a reflexão auto avaliativa e a pesquisa, que ilustramos na segunda realidade.

Após realizarmos essas considerações, nos dedicaremos doravante em buscar alguns elementos que tratem dos saberes do professor de Geografia, pois pensamos que sua formação demanda alguns conhecimentos peculiares que merecem ser explorados. Entretanto, é importante dizer que os saberes estudados até o momento são incluídos e não desconsiderados. 


\section{3}

OS SABERES DOCENTES EM GEOGRAFIA

Considerando os temas já tratados, partimos do pressuposto de que para ensinar Geografia não basta conhecer seus conteúdos, como já dissemos, fazer Geografia pressupõe conhecê-la, todavia, ensiná-la exige também conhecimentos relacionados às ciências da educação. "É inegável que o professor precisa de uma carga de informações, de conteúdos para ter condições de realizar o seu trabalho, mas é também imprescindível compreender como fazer o trato destes conteúdos em sala de aula" (CALLAl, 1995, p. 40).

Em síntese, a citação reforça o que já dissemos anteriormente, em uma formação que prepare o profissional para encarar os desafios aos quais estará sujeito, é fundamental que além de conhecer sua ciência se compreenda como ensiná-la adequadamente, considerando as demandas dos estudantes. Como por exemplo, nossa experiência na regência do estágio supervisionado, durante as aulas nos apropriamos dos saberes que competem a nossa ciência, mas na forma de trabalhar esses conhecimentos estavam presentes também os saberes profissionais.

Nossa investigação acerca dos saberes do professor de Geografia perpassa pelo conceito de Educação Geográfica. Conforme Callai (2013), atualmente as pesquisas sobre formação docente em Geografia, tanto qualitativamente quanto quantitativamente, obtiveram avanços, discutimos os significados da ciência Geográfica, o que ensinamos na escola e o principal resultado destas discussões está no conceito de Educação Geográfica, que conforme a autora:

[...] diz respeito a algo mais que simplesmente ensinar e aprender Geografia. Significa que o sujeito pode construir as bases da sua inserção no mundo em que vive e compreender a dinâmica do mesmo por meio do entendimento da sua espacialidade [...] Educação Geográfica significa, então, transpor a linha de simplesmente obter informações para realização de aprendizagens significativas [...] (CALLAl, 2013, p. 75). 
Esse conceito retrata explicitamente o que buscamos quando ensinamos Geografia, porém, para alcançarmos tal objetivo a formação inicial e continuada dos professores precisa ser tratada com zelo e seriedade pelos sujeitos envolvidos nesse processo.

Tendo em vista a necessidade de formar cidadãos para a vida, sem dúvidas o professor de Geografia tem um papel fundamental nessa tarefa, por meio da Educação Geográfica é possível dar significado ao conteúdo dessa disciplina. Nesse sentido, "A Geografia é viva e pode enriquecer a vida dos sujeitos, ressignificar conteúdos, descobrir, sonhar, acreditar, são alguns dos vários adjetivos que precisam estar presentes na profissão do professor de Geografia [...]" (MORMUL, 2018a, p. 563). Retomando qual o papel do professor de Geografia, é imprescindível

[...] organizar práticas de educação geográficas que possibilitem ao educando desenvolver raciocínios geográficos visando à construção de uma determinada consciência geográfica. Buscase, mais amplamente, contribuir para o desenvolvimento do pensamento autônomo do educando e para o favorecimento do agir cidadão no mundo [...] (LOPES, 2016, p. 34).

A Geografia é ao mesmo tempo uma ciência humana e natural, ambas alçadas ao plano da complexidade não podem ser consideradas simplesmente apêndice ou extensão da outra. Portanto, a singularidade da Geografia é produto da unidade dialética entre o meio social e o meio natural (GUGLIELMO, 1955).

O espaço como se sabe é o objeto da Geografia. Portanto, é tarefa do geógrafo interpretá-lo à luz da história, ou seja, ao longo do tempo como se deu a produção, reprodução e transformação do espaço. Fora desse horizonte de pensamento, as análises ficam comprometidas perdendo sentido prático e teórico.

Cremos que para alcançarmos uma formação crítica dos estudantes é preciso explicar os desdobramentos da relação entre meio social e natural durante a história, de que maneira as sociedades se organizam (modos de produção). Quer dizer, uma análise concreta e objetiva do espaço geográfico é imprescindível.

Ler o mundo geograficamente é a 
[....] capacidade de pensar estrategicamente o espaço geográfico, entendido como "palco" onde ocorrem as relações entre natureza e sociedade. Relações essas mediadas por razões econômicas, políticas, sociais, culturais, ambientais etc. É no entrelaçamento desses agentes que entendemos a produção sócio-espacial [...] (MORMUL, 2018b, p. 37-38).

Pensando nos conhecimentos necessários aos professores de Geografia que permitam atingir os intuitos que descrevemos anteriormente, propomos a seguir os saberes que consideramos fundamentais à prática desse profissional.

No esquema abaixo, estão reunidos os conhecimentos que neste momento acreditamos suprir as necessidades iniciais do professor de Geografia, evidente que outras variáveis influenciam na concretização da afirmação supracitada, mas esse aporte pode suscitar uma formação mais sólida, que precisa ser aprimorada constantemente a posteriori.

Esquema 1: conhecimentos necessários na formação do professor de Geografia

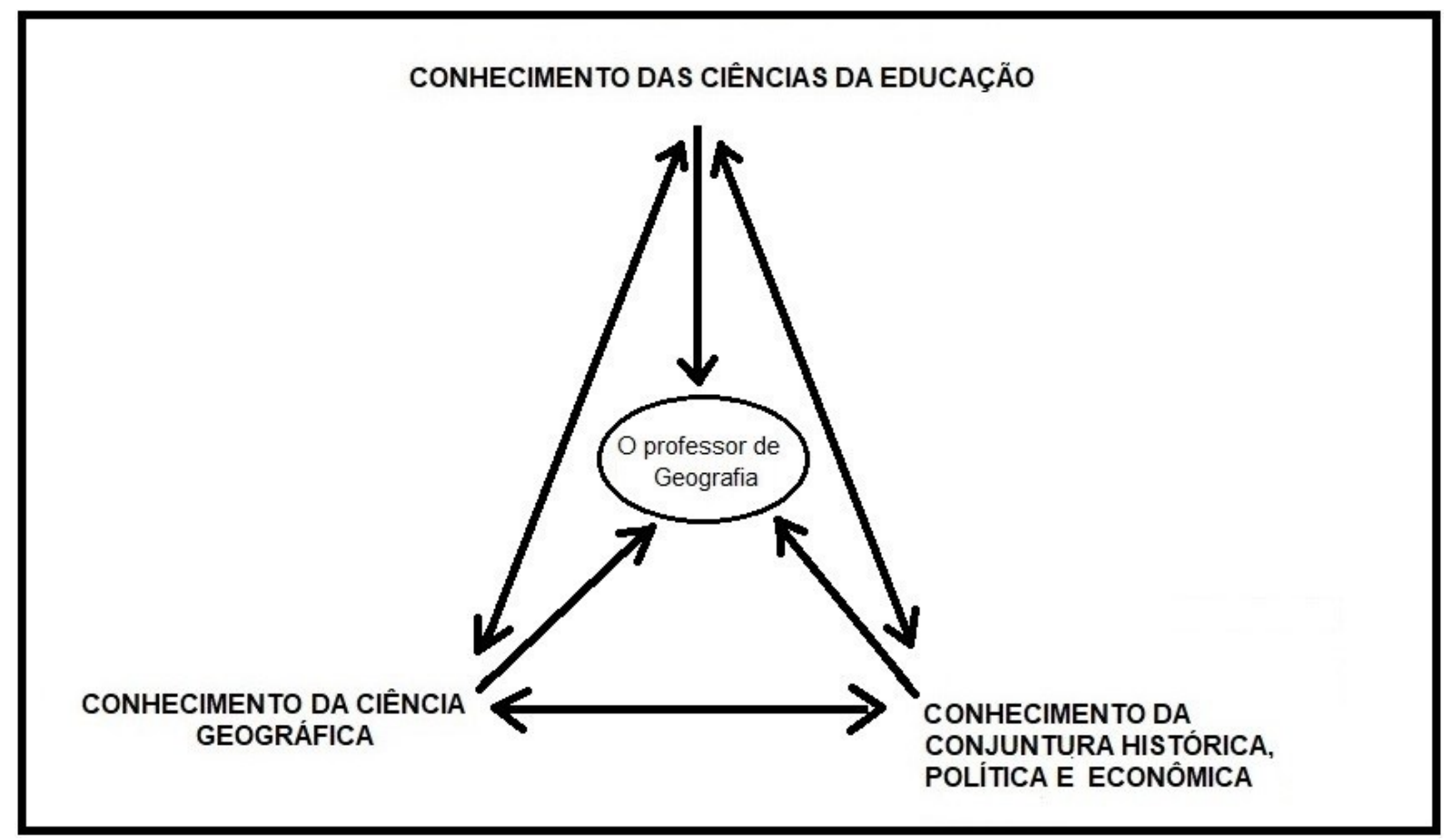

Fonte: organização dos autores, 2019 
Conhecimento da conjuntura histórica, política e econômica: dizem respeito aos conhecimentos ofertados interdisciplinarmente nos cursos de Geografia Licenciatura, estes irão ensejar ao professor compreender as características históricas da gênese, formação e organização espacial das sociedades e de suas relações com o meio. Defendemos a presença desse conhecimento na formação pois “[...] torna-se importante que o professor(a) conheça o projeto de sociedade engendrado e, assim, agir de modo lúcido e ativo no processo de ensino e aprendizagem, logo, na prática educativa como um todo [...]" (MORMUL, 2018b, p. 37).

Para nós, a categoria da Geografia que melhor responde as demandas de entendimento desse conhecimento é a categoria de Formação Sócio-Espacial (FSE) desenvolvida por Santos (1977). Ela trata do estudo daquilo que é concreto na vida de uma sociedade (a produção), ou seja, da sua realidade histórica e localizada no espaço geográfico. Ela se preocupa em decifrar a gênese e a evolução dialética das leis de funcionamento e a organização econômica-social e espacial das sociedades, que é particular, mas somente é apreendida no bojo da totalidade.

O Geógrafo Milton Santos a partir do conceito marxista de formação econômico-social, o qual segundo este autor é o mais apropriado para contribuir na formação de uma teoria do espaço, elaborou a categoria de Formação Sócio-Espacial, pois, “a História não se escreve fora do espaço e não há sociedade a-espacial. O espaço, ele mesmo, é social" (SANTOS, 1977, p. 1). De acordo com Sereni (2013, p. 332), as formações econômico-sociais "expressam a unidade dialética de continuidade e descontinuidade do processo histórico". Marx utilizou pela primeira vez a expressão formação econômico-social no prefácio da sua obra “Contribuição à Crítica da Economia Política”, publicada em 1859.

O conceito de formação social

[...] diz respeito à evolução diferencial das sociedades, no seu quadro próprio e em relação com as forças externas de onde mais frequentemente lhes provém o impulso. A base mesma da explicação é a produção, isto é, o trabalho do homem para transformar, segundo leis historicamente determinadas, o espaço com o qual o grupo se confronta (SANTOS, 1977, p. 1). 
Sereni (2013), destaca a valiosa contribuição de Lenin para o aprofundamento e merecida centralidade conferidas ao conceito de formação econômico social enquanto uma categoria fundamental para o materialismo histórico. Além disso, o autor lembra que a categoria de formação social não se restringe a analisar a teoria econômica, considera também as superestruturas decorrentes das relações de produção, como por exemplo a política.

Lenin desenvolve o conceito de formação econômico-social (2), o qual podemos caracterizar seus termos em: i) Formação: é uma realidade que muda, está em transformação, evolui de maneira histórica e objetiva; ii) Econômico-social: por econômico se entende as forças produtivas, ou seja, a relação do homem com a natureza e por social entende-se as relações de produção, isto é, a relação entre os homens (LEFEBVRE, 1969).

A categoria FSE possui três características que são centrais e não devem ser tomadas isoladamente, a saber, sintetizadas na i) noção de realidade concreta e em movimento, as leis que a regem e sua dinâmica histórica e localizada no espaço (a espacialização da história); ii) a relação dialética e contraditória dessas leis, que são gerais e particulares e iii) a noção de totalidade (os modos de organização em uma sociedade, sua combinação - peculiar - em unidade de contrários).

Esse conhecimento direciona-se também ao que Yves Lacoste (1976) denunciou em seu livro "A Geografia: isso serve, em primeiro lugar, para fazer a guerra", no qual o autor vê a Geografia estratégica, rica e política à serviço apenas da classe dominante, contudo, pretendemos que esse conhecimento científico com potencial e suas ferramentas de análise estejam disponíveis ao conjunto da sociedade.

Conhecimento das ciências da educação: são os conhecimentos referentes às ciências da educação, que aparecem em disciplinas como por exemplo, didática, políticas educacionais, fundamentos da educação, estágio supervisionado, entre outras.

Esses conhecimentos oportunizam aos futuros docentes a compreensão de alguns saberes indispensáveis nessa profissão, como por exemplo as teorias da 
aprendizagem (4), o processo de ensino e aprendizagem, as metodologias de ensino, os instrumentos pedagógicos, as diretrizes curriculares e as políticas direcionadas à educação etc., que darão suporte para que o professor desenvolva mais tarde seus próprios saberes na experiência em sala de aula.

Entender a estrutura organizacional da escola, as políticas direcionadas para a educação, os currículos e o impacto que eles exercem é fundamental para a atividade docente, uma vez que, influenciam copiosamente o a dia a dia do professor, tendo ele consciência desse fato ou não, os programas constituem as bases do seu trabalho, conhece-los pode suscitar participação efetiva na crítica, reformulação e desenvolvimento dessas diretrizes.

Nesse sentido, Pimenta (1999) corrobora com esse argumento quando afirma que “[...] para saber ensinar não bastam a experiência e os conhecimentos específicos, mas se fazem necessários os saberes pedagógicos e didáticos" (p. 24).

Tal conhecimento é fundamental para a ingresso do profissional na sua carreira, dispondo ele de conceitos, definições e elaborações teóricas que o auxiliem na realidade diante das situações que encontrará no ambiente de trabalho, possibilitando uma visão holística referente à ciência educacional.

Conhecimento da ciência geográfica: esses concernem aos conhecimentos específicos da Geografia, são as disciplinas que compõem a grade curricular do curso de licenciatura em Geografia. Esse conhecimento é imprescindível, do contrário não há Geografia, ele permite que o futuro professor adquira a capacidade de conhecer e compreender essa ciência, suas potencialidades, limites e objetivos. Também diz respeito aos conteúdos e conceitos que serão ensinados, estes que sofrem grave esvaziamento na Geografia, agora reforçado com a aprovação em 2018 da nova Base Nacional Comum Curricular (BNCC).

Apesar de tratarmos esses conhecimentos de maneira isolada na exposição, é importante destacar que nosso propósito é que os mesmos conversem, ou seja, complementem-se reciprocamente formando um conjunto de saberes que são necessários na formação do professor de Geografia. 
Defendemos também que esses conhecimentos sejam guiados pela Educação Geográfica, que não se restringe simplesmente a cumprir um rol de conteúdos, é essencial o compromisso de explicar e fazer compreender o mundo que vivemos construindo instrumentos para torná-lo mais justo, dando significado para a Geografia pela sua utilidade na vida concreta (CALLAI, 2012).

Por compreendermos a Geografia como uma ciência da relação dialética entre meio social e natural, consideramos essencial o conceito das combinações geográficas, elaborado por Cholley (1964), ele permite exatamente vislumbrar o eixo central e a especificidade dessa ciência.

Nesse sentido, é mister compreender as condições concretas e os motivos que determinam ao homem o modo como imprimi sua marca na natureza, de diferentes particularidades ao longo do tempo. Esse exercício nos parece uma tarefa desafiadora e ao mesmo tempo necessária, daí lançar uso da categoria de Formação Sócio-Espacial (FSE) e do conceito de Combinações Geográficas para decifrar esse processo.

Para produzir os meios de sua sobrevivência o homem age sobre a natureza por meio do trabalho (3), ao fazer isso transforma esta última e a si próprio, modificando as forças produtivas e as relações de produção ininterruptamente durante a história humana. Essa ação, porém, não se dá de forma automática, mecânica e homogênea no tempo e no espaço geográfico, ao contrário, ela é contraditória, dialética e desigual.

\section{CONSIDERAÇÕES FINAIS}

Ao longo deste artigo mostramos quais são os saberes necessários para o professor de Geografia exercer seu trabalho de modo a contribuir na formação dos educandos. Argumentamos que os saberes que os professores mobilizam segundo os teóricos mencionados no texto, são plurais, advém de diversas fontes sociais e ao longo da carreira são aperfeiçoados na prática da sala de aula e no contato com os sujeitos da escola. 
Essa perspectiva procura se posicionar de forma oposta à ideia de que os saberes dos professores são produzidos somente por terceiros, tendo seu trabalho guiado por pessoas distantes da sua prática no dia a dia da escola. Acreditamos que os professores agem diretamente na constituição dos seus saberes mediante a experiência no trabalho, ainda que esses saberes sejam amplamente desvalorizados. Também mostramos o contexto humano que envolve a profissão professor, não se trata de uma atividade puramente burocrática ou técnica em que predominam as relações ser humano e objeto, mas sim relações ser humano e ser humano, o que a torna a profissão complexa e ao mesmo tempo importante, desafiadora e simultaneamente carregada de responsabilidades.

Exatamente por essa característica, por se tratar de uma atividade desafiadora que a mesma necessita de uma gama de saberes que dê conta das suas exigências. Queremos afirmar com isso que o professor de Geografia, além, obviamente de dominar essa ciência, conheça também de outros saberes fundamentais ao sucesso do processo de ensino e aprendizagem.

Por fim, os saberes que consideramos indispensáveis na formação do professor de Geografia, isto é, i) o conhecimento da conjuntura histórica, política e econômica; ii) Conhecimento das ciências da educação; e iii) conhecimento da ciência geográfica. Acreditamos que a união destes em torno da Educação Geográfica, da categoria de FSE e do conceito de Combinações Geográficas é capaz de proporcionar uma formação qualificada ao docente que se propõe trabalhar com a Geografia.

\section{REFERÊNCIAS}

BRASIL. Ministério da Educação. Secretaria da Educação Básica. Base nacional comum curricular. Brasília, DF, 2018. Disponível em: http://basenacionalcomum.mec.gov.br/wp-content/uploads/2018/02/bncc-20dezsite.pdf Acesso em 10/09/2018.

CALLAI, H. C. A Formação do profissional da Geografia: o professor. Ijuí: Unijuí, 2013. 
CALLAI, H. C. A formação do professor de Geografia. Boletim Gaúcho de Geografia, 20: dez., p. 39-45, 1995.

CALLAI, H. C. Educação Geográfica: ensinar e aprender Geografia. In: CASTELLAR, Sonia Maria Vanzella; MUNHOZ, Gislaine Batista; ARROIO, Agnaldo (Orgs). Conhecimentos Escolares e Caminhos Metodológicos. São Paulo: Xamas, 2012. p. 73-87.

CHOLLEY, A. Observações sobre alguns pontos de vista Geográficos. $1^{\text {a }}$ parte, Boletim Geográfico. N 179, p. 139-145, Rio de Janeiro, 1964.

CHOLLEY, A. Observações sobre alguns pontos de vista Geográficos. $2^{a}$ parte, Boletim Geográfico. N 180, p. 267-276, Rio de Janeiro, 1964.

ENGELS, F. O papel do trabalho na transformação do macaco em homem. RocketEdition, 1999.

FRANCO, M. A. S. Prática docente universitária e a construção coletiva de conhecimentos: possibilidades de transformações no processo ensinoaprendizagem. São Paulo: USP, 2009.

GIROTTO, E. D. Entre a escola e a universidade: 0 produtivismo-aplicacionismo na formação de professores em Geografia. 2014. 237 f. Tese (Doutorado em Geografia Humana) - FFLCH-USP, 2013.

GIROTTO, E. D.; MORMUL, N. M. Formação Docente e Educação Geográfica: entre a escola e a universidade. Curitiba: CRV, 2016.

GUGLIELMO, R. Geografia e Dialética. La nouvelle critique, n 68, set./out., 1955, p. 143-155. Tradução: AGB, São Paulo.

LACOSTE, Y. A Geografia, isso serve, em primeiro lugar, para fazer a guerra. $3^{a}$ edição. Campinas, SP: Papirus, 1976.

LEFEBVRE, H. O Pensamento de Lenine. Tradução de Luis Salgado de Matos. $2^{a}$ edição. São Paulo: Moraes, 1969.

LOPES, C. S. O professor de Geografia e os Saberes Profissionais: o processo formativo e o desenvolvimento da profissionalidade. 2010. 257 f. Tese (Doutorado em Geografia Humana) - FFLCH-USP, 2014.

LOPES, C. S.. O Trabalho Pedagógico do Professor de Geografia e seus Saberes. In: PORTUGAL, Jussara Fraga; OLIVEIRA, Simone Santos de; RIBEIRO, Solange Lucas (Orgs). Formação e Docência em Geografia: narrativas, saberes e práticas. Salvador: EDUFBA, 2016. 
MORMUL, N. M. Eu professor?! Entre vivências e diálogos. Caderno de Geografia, Belo Horizonte, v. 28, n. 54, p. 552-573, jul. 2018a.

MORMUL, N. M. O Papel do Professor de Geografia na Sociedade Contemporânea. Perspectiva Geográfica, Marechal Cândido Rondon, v. 13, n. 18, p. 32-41, jan./jun., $2018 b$.

NÓVOA, A. Professores: Imagens do futuro presente. Lisboa: Educa, 2009.

PIMENTA, S. G. Formação de professores: identidade e saberes da docência. In: PIMENTA, S. G. (Org). Saberes pedagógicos e atividade docente. São Paulo: Cortez, 1999. p. 15-34.

ROLDÃO, M. C. Função Docente: natureza e construção do conhecimento profissional. Revista Brasileira de Educação, São Paulo, v. 12 n 34, p. 94-103, jan./abr., 2007.

SANTOS, M. Sociedade e Espaço: A formação social como teoria e como método. Boletim Paulista de Geografia, n 54. São Paulo, junho, 1977.

SERENI, E. DE MARX A LÊNIN: a categoria de "formação econômico-social". Meridiano, $\mathrm{n}^{\circ}$ 2. Buenos Aires, 2013.

TARDIF, M. Saberes docentes e formação profissional. 17. ed. Petrópolis: Vozes, 2014.

TARDIF, M; LESSARD, C. 0 trabalho Docente: elementos para uma teoria da docência como profissão de interações humanas. Petrópolis: Vozes, 2009.

VIGOTSKY, L. M. A Formação Social da Mente. $4^{a}$ ed. São Paulo: Livraria Martins Fontes, 1991.

\section{NOTAS:}

1- Artigo final de conclusão do curso em Geografia Licenciatura; apresentado no III Seminário Internacional de Educação XXIII Semana Acadêmica de Pedagogia: Educação e Conhecimento Científico: Construção e Resistência. Francisco Beltrão/PR - De 08 a 11 de outubro de 2019; revisado e reformulado pelos autores para essa publicação.

2- "Há leis universais do devir (dialético) - as leis gerais (da formação econômico- social) - e leis específicas, próprias de cada época, modo de produção, estrutura ou regime social. Estas leis imbicam-se, interpenetram-se reciprocamente, envolvem-se ou pelo contrário, limitam-se e excluem-se" (LEFEBVRE, 1969, p. 198).

3- "O trabalho é a fonte de toda riqueza, afirmam os economistas. O trabalho, porém, é muitíssimo mais do que isso. É a condição básica e fundamental de toda vida humana. E em tal 
grau que, até certo ponto, podemos afirmar que o trabalho criou o próprio homem" (ENGELS, 1999, p. 4).

4- "Acreditamos que o desenvolvimento da criança é um processo dialético complexo caracterizado pela periodicidade, desigualdade no desenvolvimento de diferentes funções, metamorfose ou transformação qualitativa de uma forma em outra, imbricamento de fatores internos e externos, e processos adaptativos que superam os impedimentos que a criança encontra" (VIGOTSKY, 1991, p. 51) 